\title{
¡Qué viva la democracia!
}

Sí, que viva, y la libertad también —que es congénita a la misma - pero si nos aseguramos la vida para todos y en abundancia. No la miseria de vida que nos quieren dar como limosna los ricos y poderosos.

A veces pareciera que lo único que importa es que viva la democracia, aunque vivamos muriendo. Para vivir la democracia primero hay que estar vivo, de lo contrario sólo la vivirán los otros. La democracia y la vida, la reproducción material y la libertad pareciera que son excluyentes. Pienso que está mal planteado ponerlas como opciones, debe procurarse tanto la vida como la libertad. Estas ideas son las que me han llevado a manifestar mi desacuerdo con aquellos que apologetizan la democracia.

Por razones que no tiene caso considerar, me parece que existe una tendencia a deificar ciertas categorías, a manera de ejemplos cabe mencionar el estado de derecho, la empresa privada, el mercado, la cultura occidental y, particularmente, la democracia. Casi parece que la tal democracia se ha convertido en sinónimo de paraíso y que, en consecuencia, resultaría incuestionable, ya que de hacerlo sería indicativo de demencia o, en el mejor de los casos, induciría a ser considerado como un auténtico hereje, con lo cual, obviamente, se buscaría la descalificación de quien o quienes se atrevieran a dudar o cuestionar tan cara irrealidad.

Uno de los defensores anónimos de esta presunta fe democrática sostenía recientemente en un escrito publicado en Carta a las Iglesias:
No faltan quienes, ante la avalancha de hechos criminales y la impunidad que rodea a muchos de ellos, reniegan de la democracia y llegan al extremo de afirmar que ésta no sirve de nada, pues está integrada por formalismos vacíos que dejan inatacados los problemas reales que cotidianamente enfrentan los habitantes de El Salvador'.

Para luego, tranquilamente, deducir que quienes lo hacen así están a favor del autoritarismo, sin percatarse que en ese juego a favor de la democracia, de igual manera se les podría endilgar que lo que están defendiendo no es a la democracia sino al sistema, pero que lo hacen de manera vergonzante porque al no pertenecer a la clase dominante y moverse en un ambiente como el de la UCA, como que no les corresponde ser los adalides de un sistema mezquino, inhumano e injusto.

Ciertamente, para quienes tienen resuelto el problema de su reproducción material e ideológica resulta molesto, e inclusive intolerable, que se cuestione al régimen democrático. Pero para quienes la reproducción material no es un supuesto sino una realidad que es preciso asegurar día con día, las "normas" y los "valores" de la nunca bien ponderada democracia no tienen mayor sentido y mucho menos alguna importancia, de allí que la democracia que se presenta como poseedora de un valor absoluto en sí misma, no pasa de ser algo relativamente valorable.

Podría creerse que la democracia es buena y deseable en sí misma debido a que, como dice el

1 La Transición Democrática, Carra a las Iglesias, 16-30 de septiembre, 1997. 


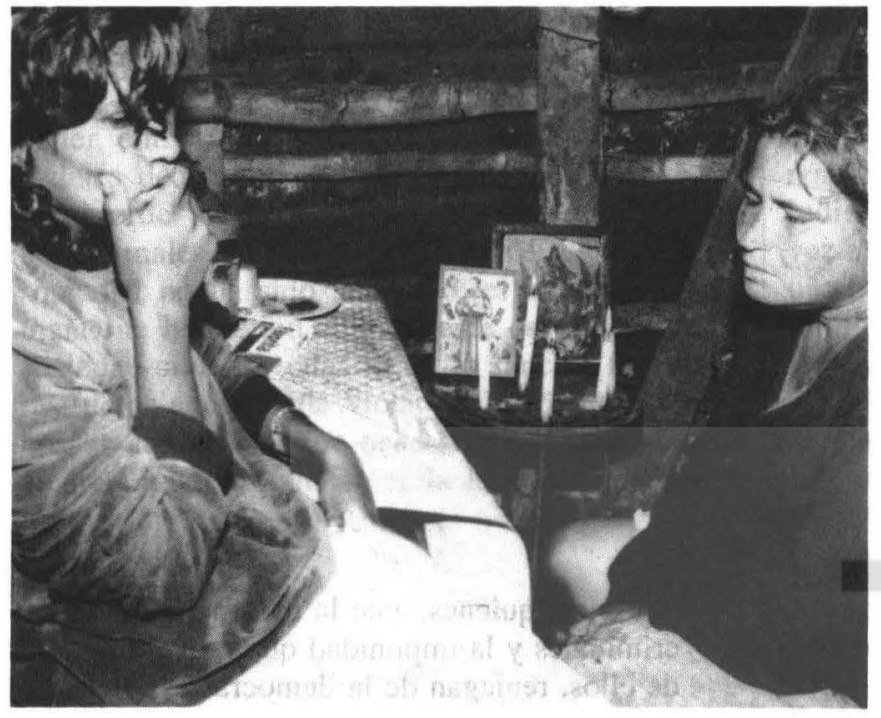

debería ser un elemento clave de cualquier régimen de convivencia humana. Régimen que no liene porqué ser necesariamente eso que se llama democracia y que malamente se practica en algunos de sus elementos acá entre nosotros, tales son, por ejemplo, aquellos vinculados a las elecciones de algunos funcionarios de los Organos Ejecutivo y Legislativo.

Son muchos, quizá hasta la mayoría, aquellos para quienes las decisiones de la mitad más uno casi asumen un carácter sagrado y consecuentemente se torna inapelable - ya no se diga cuando se trata de la mayoría calificada- pero, ¿quién le garantiza sabiduría, justicia y generosidad a las decisiones mayoritarias? ¿Por qué un elemento cuantitativo

escritor que comentamos, gracias a la democracia ahora no se asesina a nadie por sus ideas. A lo cual cabría responder que en rigor nunca y en ninguna parte se ha asesinado a nadie a causa de sus ideas, ya que las ideas sólo constituyen una posible fuente de problemas cuando se expresan. El pensar, mientras no pase de allí, a nadie preocupa ni ocupa.

Pero antes de referirme a situaciones extremas relativas a la vida y la muerte, cabría preguntarnos si efectivamente existe en El Salvador de hoy libertad de expresión del pensamiento para todos, incluyendo a quienes son considerados como antisistema, porque si se va a hacer la gran alharaca de los Acuerdos de Paz porque pueden expresarse libremente los adeptos al sistema, déjenme decirles que ello no presenta ninguna novedad y no es indicativo de nada. En ese sentido, no vale poner como ejemplo de libertad de expresión el hecho de que algunos supuestos exguerrilleros tengan acceso ahora a las páginas editoriales de un matutino local para expresar sus ideas y opiniones, las cuales son muy acordes y siempre están muy bien enmarcadas dentro de los requerimientos e intereses del sistema. Y, como se sabe, para los conversos siempre ha existido un lugar donde puedan practicar su nueva fe.

Me parece que un clima de democracia comienza por no descalificar a quienes no comulgan con el sistema, ya que desde el momento de hacerlo se está negando el derecho a disentir, el cual va a generar tanta calidad? Evidencia sobre lo irracional y absurdo de este proceder se observa en los resultados de las elecciones, mediante las cuales se eligen servidores públicos incapaces y corruptos, pero eso sí, muy populares ya que han contado con el beneplácito de la mayoría.

Pero lo más lamentable de todo esto radica en que vamos aceptando que nos rijan los criterios irracionales, para el caso, cuando se piensa en posibles candidatos a diputados, alcaldes o presidente de la república, por ejemplo, no preguntamos si la persona tiene capacidad, si es honesta, si no abusa de los débiles, si es justa, etc. En el perfil de un posible candidato no destacan los valores ni la capacidad, lo único que importa es que aparezca muy bien ranqueado en términos de popularidad en las encuestas de opinión.

Los criterios por considerar son determinados no por las personas capaces, sabias y honestas, sino por la opinión de la mayoría, ya que para ganar las elecciones lo importante es contar con muchos votos, con suficientes votos para ganarle a los otros candidatos. Por ello es que las encuestas de opinión se toman muy importantes, adquieren mucha más importancia de la que en realidad tienen por lo que son. Pero, ¿qué es lo que ha sucedido? ¿Por qué resulta tan importante la opinión pública al punto de que haya personas que se ganan la vida auscultándola? ¿Por qué, incluso, se vende a los candidatos como si fuese mercadería? Veamos.

El capitalismo funciona por medio del merca- 
do. Para poder triunfar es importante conocer cuál es la opinión de la mayoría de los consumidores, ya que al conocerla es posible producir en las cantidades debidas aquello que la mayoría demanda. Tal mecanismo resulta rentable para el fabricante, ya que al atender al mercado puede maximizar sus beneficios y minimizar sus costos, y si todos los fabricantes consiguen hacerlo, se habrá conseguido una asignación eficiente de los recursos escasos, razón por la cual deberíamos estar felices y contentos; sin embargo, tal mecanismo de funcionamiento mercantil crematístico no brinda resultados satisfactorios cuando se aplica al funcionamiento de la sociedad, ya que no sólo se producen gobernantes incapaces y corruptos, sino que se condena a la mayoría de la población misma a terribles condiciones de miseria material, intelectual y espiritual. Con el triste y fatal desenlace de que el sistema no sólo logra garantizar su reproducción, sino que las posibilidades de pensar en un cambio necesario se tornan remotas, ya que los pocos que no están embrutecidos por los criterios mercantil cremalísticos terminan aceptando los criterios de la mayoría embrutecida.

$Y$ es que al igual que a los consumidores de mercancías, a los electores en la democracia también se les manipulan sus voluntades y sus conciencias, lo cual se traduce en la existencia de grandes masas alienadas capaces de llevar al poder a sus auténticos enemigos de clase o, dicho con otras palabras, a aquellos que tienen intereses económicos y sociales totalmente opuestos a los suyos.

Antes y durante los períodos de campañas polílicas, los medios de comunicación social se ven saturados con los mensajes de los políticos en el gobierno y los de aquellos que quieren llegar al gobierno. Y es que el gobierno en El salvador, aunque a Mena Lagos no le parezca, está y ha estado siempre al servicio de los grupos oligárquicos, aunque estos no siempre hayan detentado directamente el poder, razón por la cual segura- mente no resultaba tan evidente como lo es ahora en que los oligarcas fungen como políticos. Y valga la ocasión para aclararle a Mena Lagos que tan político es él como Cristiani, aunque él no controle ningún partido y Cristiani sí.

La democracia que tanto aman algunos, la democracia de occidente, la democracia que funciona en el interior del régimen capitalista posee inconvenientes bastante serios que es preciso considerar, por ejemplo, en la medida en que se tiene poder económico se tiene poder político, social, ideológico, jurídico, etc. En consecuencia, cuanto más poder económico se posea, más poderes derivados se tendrá y, por lo mismo, se gozará de mayores derechos, privilegios e incluso se llegará a gozar hasta de impunidad. Si no se tienen rique$z a s$, no se tiene ningún poder económico $y$, por tanto, no se tiene absolutamente nada. Pero entre ambos extremos existe toda una gama de poderes, los cuales pueden ser muy grandes, grandes, medianos, pequeños, chicos, muy chicos e insignificantes. Entre los gigantes y los grandes, a menudo surgen contradicciones que generan luchas que cobran gran importancia en el plano nacional, ya que todo lo que ocurre entre los poderosos tiene un gran poder de atracción. Los insignificantes gozan del espectáculo y hasta llegan a sentirse importantes cuando alguno de los grandes es derrotado; los de en medio se sienten con derecho a opinar acerca de los litigios entre los grandes y gigantes, lo cual parece dotarlos de una significación que de suyo no poseen.

Mientras la opinión pública está ocupada con este espectáculo, nadie se acuerda de los problemas de pobreza, desempleo, violencia, etc. que padecen las grandes mayorías y hasta pareciera que ya no existen. Eso es muy del agrado de quienes pueden disfrutar sin angustia de lo maravillosa que es la democracia.

Aquiles Montoya 